\title{
Onomástica organometálica. 2. Richard F. Heck: o americano tranquilo e a sua reação revolucionária
}

\author{
Carlos C. Romão \\ Instituto de Tecnologia Química e Biológica António Xavier, ITQB NOVA, Av. da República, 2780-157, Oeiras, Portugal
}

\begin{abstract}
Organometallic Onomastics. 2. Richard F. Heck: the quiet American and his revolutionary reaction - The late 1970s witnessed a tremendous revolution in the way complex organic structures were assembled due to the emergence of a series of new catalytic $C-C$ coupling technologies. On the background of these technologies rests the Heck reaction, discovered by Richard F. Heck, published in its original form in 1967 and later perfected to its actual shape in 1974. Making this discovery as a researcher at an explosives factory, Hercules Powder Company, Heck had a crucial role in the development of organometallic homogenous catalysis and its use in organic synthesis. His aloof and modest attitude kept him out of the academic limelight while watching the astonishing repercussion of his discoveries. A late Nobel Prize finally brought him the deserved recognition, which he acknowledged with a quiet and clear conscience of having contributed his share to the History of Chemistry.
\end{abstract}

O final da década de 1970 testemunhou uma tremenda revolução na forma de sintetizar estruturas orgânicas complexas devido ao aparecimento duma série de novas tecnologias de acoplamento C-C. Por detrás destas tecnologias encontra-se a reação de Heck, descoberta e publicada em 1967 por Richard F. Heck, e por ele aperfeiçoada para a sua forma atual em 1974. Fazendo esta descoberta como investigador numa fábrica de explosivos, a Hercules Powder Company, Heck teve um papel crucial no desenvolvimento da catálise homogénea organometálica e no uso desta em síntese orgânica. A sua postura reservada e modesta manteve-o afastado da ribalta académica, mas sempre atento à espantosa repercussão das suas descobertas. Um Prémio Nobel tardio trouxe-lhe finalmente o merecido reconhecimento, que ele aceitou duma forma discreta mas com a clara consciência da importância da sua contribuição para a História da Química.

A montagem de estruturas orgânicas complexas através de metodologias organometálicas de formação de ligações C-C é uma realidade incontornável na atual estratégia de síntese. Tais processos aparecem ao estudante que os contempla pela primeira vez como uma espécie de caixa preta, ou instrução de computador para realizar uma operação que poderia ser fastidiosa e mesmo um quebra-cabeças se tivesse de ser resolvida pelos métodos que se ensinavam nos tempos em que estudei química orgânica nos finais dos anos 1960. Não sei mesmo se essas metodologias já aparecem no ensino de graduação, mas são seguramente ministradas no ensino graduado. O nome geral destas metodologias é “reações de acoplamento de fulano de tal”. Os "fulanos de tal" são quase todos japoneses mas o verdadeiro responsável por esta fulanização é o químico americano Richard F. Heck inventor da reação de Heck (eq. 1) que iniciou uma das maiores revoluções metodológicas já ocorridas na prática da síntese orgânica.

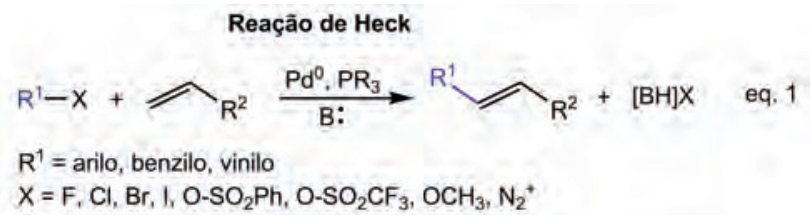

Richard F. Heck nasceu em Springfield, Massachussetts em 1931 e cruzou os EUA para se doutorar (1954) na UCLA (Universidade da California, Los Angeles), sob a orientação de Saul Winstein, um proeminente químico-físico orgânico.

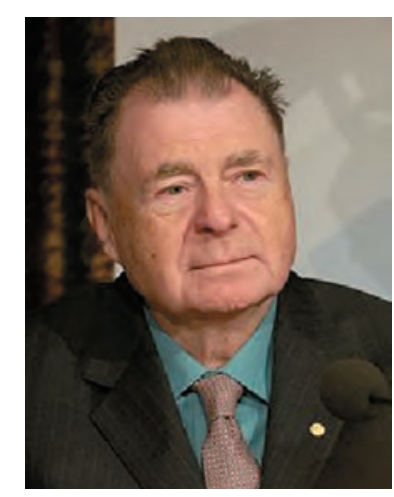

Figura 1 - Richard Heck em 2010.

Novo salto de fronteiras levou-o até Zurique para um ano de pós-doutoramento numa das melhores escolas de química do mundo, sob a orientação doutra sumidade: Vladimir Prelog na ETH. Retornou à UCLA por mais um ano mas, apesar desta formação académica "vintage”, regressou à costa leste para trabalhar no departamento de investigação da Hercules Powder Company, em Wilmington, Delaware. Pode parecer estranho, dentro das expectativas que (erradamente) teremos da investigação numa fábrica de armamento e combustíveis para foguetões, que uma fábrica de pólvora estivesse interessada em química organometálica. O certo é que Heck, depois de dois anos falhados de investigação em polimerização de monómeros vinílicos, foi convidado a abordar a hidroformilação catalítica de olefinas representada na (eq. 2). Esta reação, que como o nome indica adiciona formalmente $\mathrm{HCHO}$ a uma ligação C=C, foi descoberta em 1938 por Otto Roelen na Alema- 
nha, constituindo um dos primeiros e maiores sucessos de sempre da catálise organometálica industrial [1].

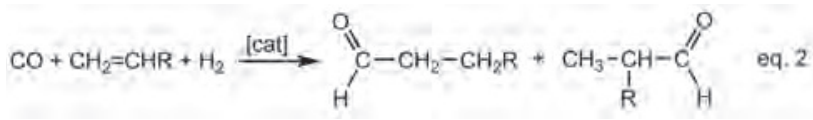

A descoberta da hidroformilação de olefinas (alcenos) teve origem nos estudos de transformação catalítica de CO, cujo arquétipo é a reação de Fischer-Tropsch que sintetiza hidrocarbonetos a partir de misturas de $\mathrm{CO}$ e $\mathrm{H}_{2}$ (gás de síntese). A natureza do catalisador, $\mathrm{HCo}(\mathrm{CO})_{4}$, foi reconhecida logo de início, mas as peripécias por que passou a indústria química alemã durante e após a segunda guerra mundial não deram espaço ao estudo do seu mecanismo, que se manteve obscuro. Em 1960 Heck e Breslow (seu supervisor na Hercules), propuseram que o primeiro passo da reação catalítica fosse a adição de $\mathrm{HCo}(\mathrm{CO})_{4}$ ao alceno de acordo com a eq. 3 [2].

$\mathrm{HCO}(\mathrm{CO})_{4}+\mathrm{CH}_{2}=\mathrm{CHR} \rightleftharpoons(\mathrm{CO})_{4} \mathrm{Co}_{2}\left(\mathrm{C}_{2} \mathrm{H}_{4} \mathrm{R}\right) \quad$ eq. 3

Em 1961, um estudo mais aprofundado levou-os a demonstrar que essa adição era precedida pela dissociação de $\mathrm{CO}$, propondo que o complexo coordenativamente insaturado $\left[\mathrm{HCo}(\mathrm{CO})_{3}\right]$ (2; 16 eletrões; 16 e) fosse o verdadeiro catalisador das reações seguidamente observadas: formação de aldeídos (hidroformilação) e isomerização do alceno.
Tomemos como exemplo a hidroformilação do pent-1eno (esquema 1). A dupla ligação $\mathrm{C}=\mathrm{C}$ adiciona-se ao complexo insaturado 2 para dar um complexo $\pi$ (3; saturado, 18 e) que consoante a posição relativa das ligações $C=C$ e Co-H evolui para formar os alquil-complexos coordenativamente insaturados 4 ou 5 (16e). Este passo envolve uma reação de migração do hidreto para um dos átomos da ligação $\mathrm{C}=\mathrm{C}$, chamada inserção migratória. Esta migração é reversível por um processo conhecido como eliminação $\beta$. Neste caso, o complexo 5 tem duas possibilidades de evoluir: ou retorna ao complexo inicial de pent-1-eno (3) ou forma o complexo (6) o qual pode reagir com CO para formar $\mathrm{HCo}(\mathrm{CO})_{4}$ e libertar pent-2-eno. O resultado deste processo é a indesejada isomerização de algum pent-1-eno em pent-2-eno, que se observa experimentalmente nas reações de hidroformilação.

O processo principal no caminho da formação de aldeídos continua com a adição reversível de CO aos complexos insaturados 4 e 5, para originar as espécies 7 e 9 respetivamente. A migração do ligando alquilo para um CO adjacente gera os acil-complexos coordenativamente insaturados 8 e 10. Por fim, estes complexos reagem com $\mathrm{H}_{2}$, para formar os aldeídos 11 e 12, respetivamente, e regenerar o catalisador 2. Note-se que esta reação de hidrogenólise é inibida por CO, tal como a transformação $\mathbf{1} \rightarrow \mathbf{3}$ e todo o processo de isomerização do esquema 1.

Como se vê, formam-se dois tipos de aldeídos: um aldeído linear 11 e outro ramificado 12. O controlo da formação relativa de isómeros lineares vs. ramificados foi o

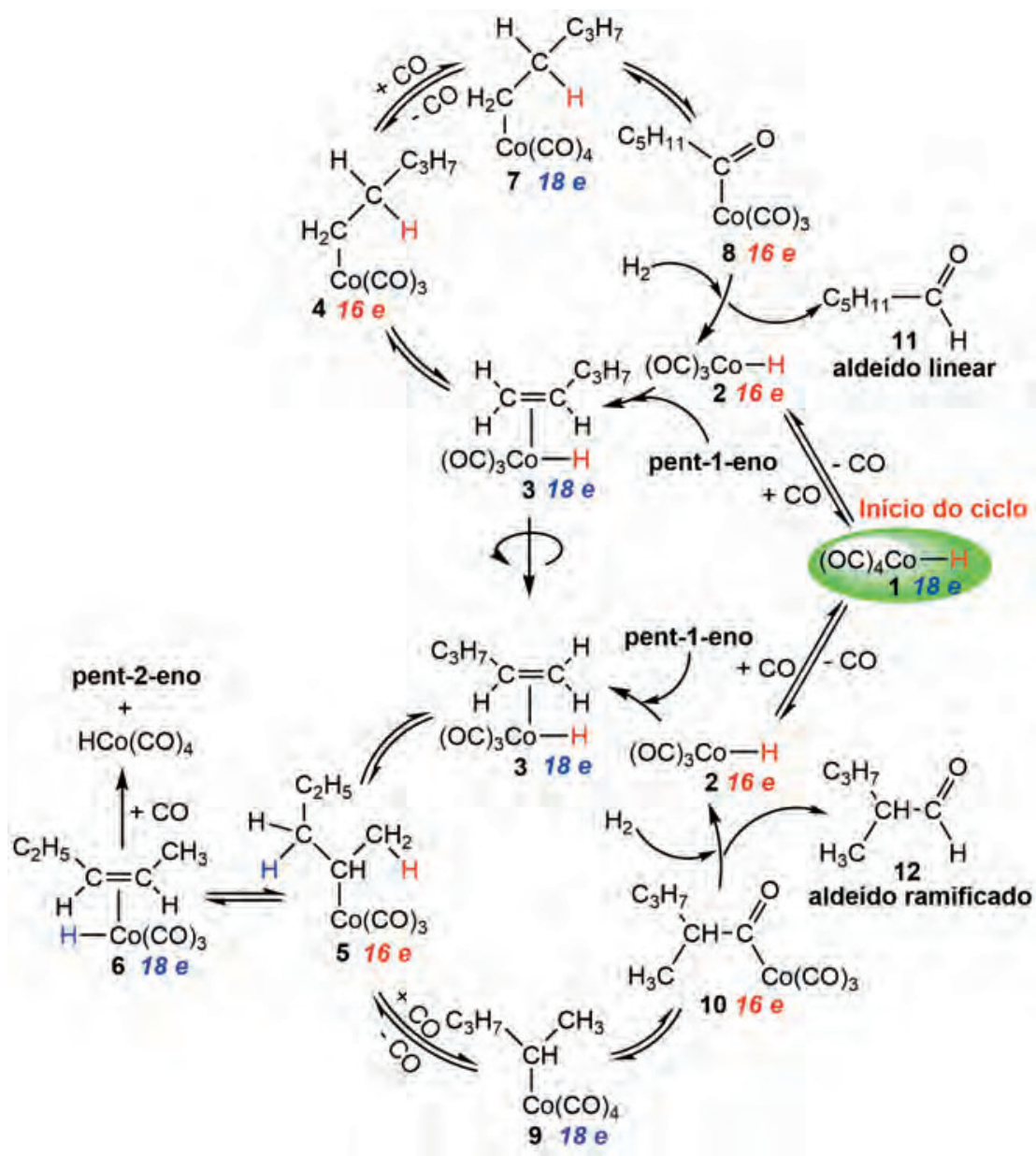

Esquema 1 - Mecanismo da reação de hidroformilação de alcenos, o primeiro mecanismo catalítico correto dum processo organometálico. 
ponto central da investigação subsequente sobre a hidroformilação, e envolve aspetos estereoquímicos e eletrónicos. Estes aspetos podem ser controlados substituindo alguns dos ligandos CO do catalisador 2 por outros ligandos, como fosfinas, que modulam a reatividade da ligação Co-H e o espaço da esfera de coordenação. Se, por exemplo a fosfina for muito volumosa, num catalisador do tipo $\mathrm{HCo}(\mathrm{CO})_{2}\left(\mathrm{PR}_{3}\right)$, a limitação de espaço livre na esfera de coordenação favorecerá a formação de aldeídos lineares visto que os isómeros ramificados requerem mais espaço e estão portanto estereoquimicamente impedidos. O metal também acabou por ser substituído por Rh, mas a fascinante discussão de todos os parâmetros que controlam a hidroformilação catalítica não cabe neste texto.

Do que foi dito importa reter duas noções. A primeira é a de que esta reação constitui o maior processo industrial de catálise homogénea e é responsável pela produção de 6,8 Mton/ano de aldeídos e álcoois usados como matéria-prima industrial. As instalações mais modernas operam em meio aquoso, mediante o uso de catalisadores solúveis em água. A segunda é a de que, na sua aparente simplicidade, este mecanismo é considerado o primeiro mecanismo correto dum processo de catálise organometálica. Ao estabelecer que todos os passos deste mecanismo envolviam um intermediário coordenativamente insaturado, Heck mostrou que a reação principal e a reação colateral ocorrem por uma sucessão de transformações de espécies de 18 eletrões (saturadas) em espécies de 16 eletrões (insaturadas), ou vice-versa, tal como assinalado no esquema 1. Hoje em dia este mecanismo parece evidente pois uma das primeiras coisas que os estudantes de Química Organometálica aprendem é a regra dos 18 eletrões logo seguida das regras de Tolman (publicadas em 1972) que dizem que as reações catalíticas não radicalares ocorrem por passos de $18 \rightarrow 16 \rightarrow 18$ eletrões ou $16 \rightarrow 14 \rightarrow 16$ eletrões no caso dos catalisadores quadrangulares planos $\mathrm{d}^{8}\left(\mathrm{Rh}^{\mathrm{I}}, \mathrm{Ir}^{\mathrm{I}}, \mathrm{Pd}^{\mathrm{II}}, \mathrm{Pt}^{\mathrm{II}}\right)$. Deve-se a Heck o aparelhar da pedra angular onde assentam estes princípios [3].

Um outro aspeto interessante deste trabalho é a forma como Heck apresenta as reações de adição do hidreto à ligação $\mathrm{C}=\mathrm{C}$ e à adição de alquilos ao CO coordenado. Estas reações são normalmente conhecidas como reações de inserção, respetivamente do alceno na ligação $\mathrm{M}-\mathrm{H}$ e do $\mathrm{CO}$ na ligação $\mathrm{M}-\mathrm{CR}_{3}$. Heck não as chama assim e usa o termo adição. Só anos mais tarde é que o estudo do mecanismo íntimo deste tipo de reações levou a que passassem a ser chamadas reações de inserção migratória de hidreto ou alquilo pois há uma migração de $\mathrm{H}$ ou $\mathrm{R}$ para o alceno coordenado numa posição adjacente. A reação inversa da inserção migratória do hidreto no alceno (e.g. $4 \rightarrow 3,5 \rightarrow$ 3 ou $5 \rightarrow \mathbf{6}$ ) era já conhecida por eliminação $\beta$ sendo típica de ligações $\mathrm{M}-\mathrm{C}_{\mathrm{n}} \mathrm{H}_{2 \mathrm{n}+1}(\mathrm{n}>1)$ que eram normalmente muito instáveis.

Uma outra descoberta de Heck, realizada no âmbito desta investigação, foi a do primeiro complexo «-alilo (13) (esquema 2) [4].

Com a sua ligação deslocalizada, identificada por $\mathrm{RMN}$, este complexo representava um tipo totalmente novo de ligação química, com os três átomos de $\mathrm{C}$ do alilo praticamente equidistantes do Co central (coordenação tri-hapto, $\eta^{3}$ ). A sua possibilidade de variar a coordenação

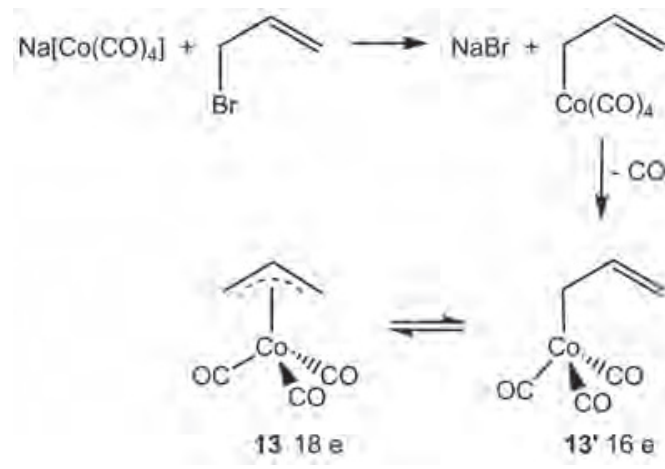

Esquema 2 - Síntese do primeiro complexo alílico $\left[\mathrm{Co}\left(\eta^{3}-\mathrm{C}_{3} \mathrm{H}_{5}\right)(\mathrm{CO})_{3}\right]$ (13) e equilíbrio com o seu isómero coordenativamente insaturado $\left[\mathrm{Co}\left(\eta^{1}-\mathrm{C}_{3} \mathrm{H}_{5}\right)(\mathrm{CO})_{3}\right]\left(13^{\prime}\right)$.

$\eta^{3} \rightleftharpoons \eta^{1}$ deu ao ligando alilo um papel destacado na química do Pd (e doutros metais) na qual Heck posteriormente construiria a sua carreira.

No dia 7 de dezembro de 1967, a partir do seu laboratório no centro de investigação da fábrica de pólvora Hercules, entretanto chamada Hercules Inc., Heck submeteu ao Journal of the American Chemical Society seis artigos, como único autor, descrevendo uma série de reações de arilos e alquilos de metais de transição com alcenos, álcoois alílicos e compostos vinílicos, dienos conjugados e CO para produzir uma grande variedade de alcenos monoméricos cujas duplas ligações $\mathrm{C}=\mathrm{C}$ ostentam agora substituintes arilo ( $\mathrm{Ar}$ ) ou alquilo $(\mathrm{R})$ como se representa no esquema 3 [5-10].

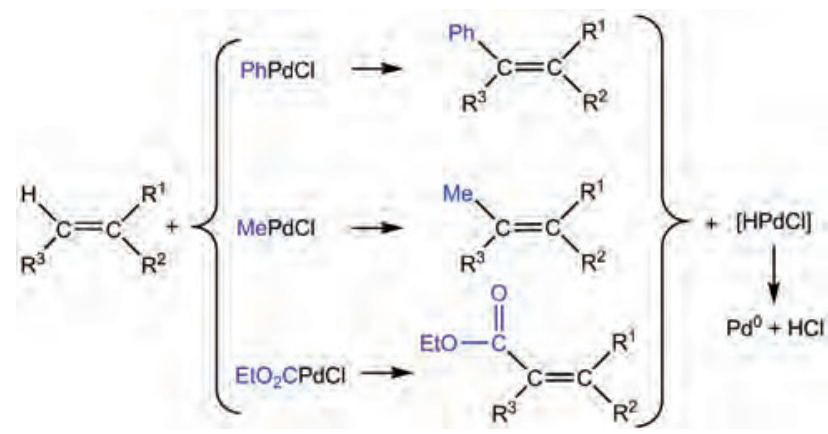

Esquema 3 - Principais tipos de ligações C-C formadas por reação de alcenos com compostos organometálicos de Pd gerados in situ por ação de organometálicos de $\mathrm{Hg}$ (eq. 4). O Pd era usado em quantidades estequiométricas e reduzido a Pd metálico.

No primeiro, e mais importante artigo desta série, Heck revela que este estudo foi estimulado pela observação de que o número de adições de alquilos metálicos a alcenos era então extremamente limitado (só apresenta dois exemplos da literatura) exceto nos processos de polimerização de olefinas (o processo de Ziegler-Natta já tinha 15 anos) [5]. No seu entender era óbvio que o potencial para adicionar alquilos ou arilos a alcenos existia para além da polimerização, mas não estava explorado. O resultado foi ainda mais saboroso do que inicialmente se esperava pois a reação permitiu substituir um protão dum alceno por um anel aromático ou por um alquilo num único passo: a arilação $(\mathrm{HC}=\mathrm{C} \rightarrow \mathrm{ArC}=\mathrm{C})$ ou alquilação $(\mathrm{HC}=\mathrm{C} \rightarrow \mathrm{RC}=\mathrm{C})$ direta de alcenos. A reação pode ser feita sob atmosfera normal, com $\mathrm{O}_{2}$ e humidade, e mesmo em água, podendo originar rendimentos quase quantitativos em muitos casos. Os me- 
tais de transição usados foram Pd, Rh e Ru, sendo que o Pd foi o mais ativo e o único que catalisou todas as reações descritas. Os arilos e alquilos de Pd foram preparados in situ a partir da reação de cloretos e outros sais de $\mathrm{Pd}^{\mathrm{II}}$, com arilos ou alquilos de metais dos grupos principais, nomeadamente $\mathrm{Hg}^{\mathrm{II}}, \mathrm{Sn}^{\mathrm{IV}}, \mathrm{Pb}^{\mathrm{IV}}$. O caso particular da eq. 4 ilustra a essência do caso geral: o agente arilante de Hg reage com um sal derivado de $\mathrm{PdCl}_{2}$ para dar um "arilo de $\mathrm{Pd}$ ” e um sal de $\mathrm{Hg}$. "PhPdCl” é o arilo de $\mathrm{Pd}^{\mathrm{II}}$ que vai ser adicionado aos substratos insaturados acima mencionados.

$\mathrm{Li}_{2} \mathrm{PdCl}_{4}+\mathrm{PhHgCl} \longrightarrow$ "PhPdCl $+\mathrm{HgCl}_{2}+\mathrm{LiCl}$ eq. 4

Tal como posto em relevo no esquema 3, a reação de arilação do alceno é acompanhada pela formação de Pd metálico e HCl. Este processo, embora valioso do ponto de vista da funcionalização da olefina tem o inconveniente de usar uma quantidade estequiométrica de Pd, um elemento muito caro. Nesse mesmo artigo Heck propôs uma solução para o problema reoxidando o $\mathrm{Pd}^{0}$ a $\mathrm{Pd}^{\mathrm{II}}$ por adição de $\mathrm{CuCl}_{2}$, que se reduz a $\mathrm{CuCl}$. Como este se reoxida a $\mathrm{CuCl}_{2}$ na presença de $\mathrm{O}_{2}$ e $\mathrm{HCl}$, o processo pode ser tornado catalítico tanto em Pd como em $\mathrm{Cu}$. O mecanismo da reação pode então ser escrito como no esquema 4.

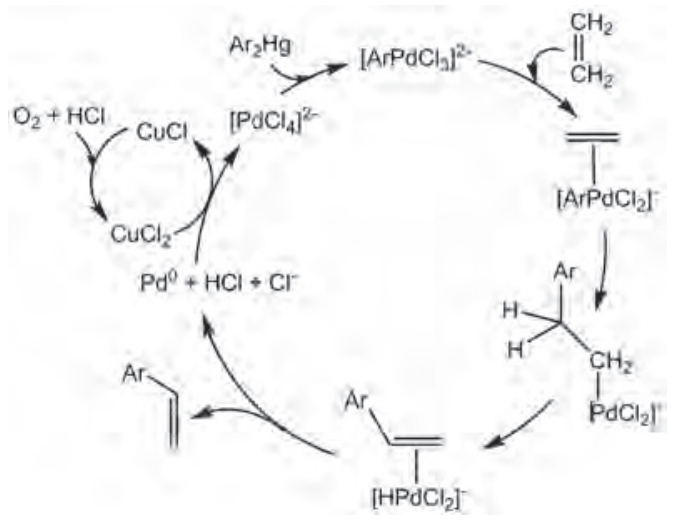

Esquema 4 - Mecanismo proposto para a primeira reação de Heck (1967). Os arilos foram escolhidos porque não sofrem eliminação $\beta$.

Como é evidente, o ponto fraco da reação era o uso de agentes arilantes de $\mathrm{Hg}$, $\mathrm{Sn}$ ou $\mathrm{Pb}$ cuja toxicidade é notória. Talvez por isso, o impacto deste artigo não foi logo sentido, mas a força da catálise organometálica espalhava-se rapidamente e havia quem estivesse atento. De facto, em 1971 numa comunicação de uma página, Mizoroki referindo o trabalho de Heck relatou a preparação do estilbeno pela reação descrita na eq 5 [1].

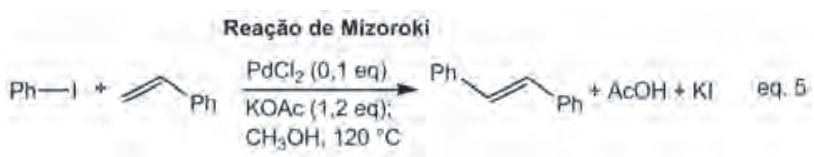

Esta reação tem lugar a alta temperatura em autoclave em condições em que o $\mathrm{PdCl}_{2}$ se reduz a $\mathrm{Pd}^{0}$. Este sofre a adição oxidativa de $\mathrm{Ar}-\mathrm{I}$ formando a espécie do tipo $\mathrm{Ar}-\mathrm{Pd}^{\mathrm{II}}$ sem necessidade de usar agentes arilantes de $\mathrm{Hg}$ ou Sn. Mais importante ainda é o facto de a reação ser automaticamente catalítica, desde que o HI que se forma seja neutralizado por uma base conveniente e não compita com o
ArI pela adição oxidativa ao $\mathrm{Pd}^{0}$. Assim, as quantidades estequiométricas de $\mathrm{PdCl}_{2}$ usadas inicialmente por Heck deixam de ser necessárias bem como o uso de $\mathrm{Cu}^{\mathrm{II}}$ para reoxidar o $\mathrm{Pd}^{0}$. De facto, Mizoroki provou que $\mathrm{Pd}^{0}$ preparado in situ (Pd black) é um catalisador ativo da reação da eq 5. Infelizmente, Mizoroki adoeceu pouco depois e não voltou a participar ativamente nestes desenvolvimentos, falecendo em 1978. Apesar disso, o seu nome não foi totalmente esquecido pois a reação de Mizoroki-Heck é o nome muitas vezes dado à reação de Heck.

Entretanto, em 1971 Heck deixava a Hercules ingressando na Universidade de Delaware onde continuou esta pesquisa. Logo no início de 1972, citando Mizoroki, publicou uma reação semelhante, obtida independentemente, mas com várias vantagens práticas: usa $\mathrm{NBu}_{3}$ como base e $10 \%$ de $\mathrm{Pd}(\mathrm{OAc})$, como percursor catalítico. Este é reduzido pelo alceno a $\mathrm{Pd}^{0}$, a $100{ }^{\circ} \mathrm{C}$ e à pressão atmosférica, e ativa iodetos de arilo adicionando-os ao estireno e outros alcenos, na ausência de solvente. Ao contrário do método que usa reagentes de Hg (esquema 4), esta reação não adiciona $\mathrm{MeI}$ ou $\mathrm{ICH}_{2} \mathrm{COOMe}$ e é portanto exclusiva para a arilação [12].

O grande salto seguinte deu-se quando Heck introduziu fosfinas na reação. Facilitando a redução de $\mathrm{Pd}(\mathrm{OAc})_{2} \mathrm{e}$ estabilizando as espécies de $\mathrm{Pd}^{0}$ e $\mathrm{Pd}^{\mathrm{II}}$ a reação de Heck tomou a sua forma definitiva (eq 1) [13]. Este estudo baseou-se numa observação de outros autores que verificaram que ArBr se adiciona rapidamente a $\mathrm{Pd}\left(\mathrm{PPh}_{3}\right)_{4}$ mas não a $\mathrm{Pd}$ metálico, como o que se forma no processo de Mizoroki. Assim, a introdução de $\mathrm{PPh}_{3}$ na mistura reacional na proporção de $\mathrm{Pd}(\mathrm{OAc})_{2}: \mathrm{PPh}_{3}=1: 2$ tornou viáveis as reações de acoplamento com brometos de arilo e vinilo que são muito mais fácies de sintetizar do que os correspondentes iodetos. Na prática verificou-se que a $\mathrm{PPh}_{3}$ era a melhor das fosfinas testadas e melhor do que uma larga panóplia de outros ligandos de $\mathrm{P}$ e $\mathrm{N}$ adicionados à reação para o mesmo efeito. Na presença de $\mathrm{PPh}_{3}$ a formação de produtos de isomerização é fortemente inibida e a estereosseletividade da reação aumentada. O mecanismo atualmente aceite está representado no esquema 5 na sua versão neutra, i.e. com todos os intermediários isentos de carga.

Sem espaço para entrarmos em detalhes sobre esta reação deixam-se aqui algumas das suas características fundamentais. As ligações $\mathrm{X}-\mathrm{C}\left(\mathrm{sp}^{2}\right)(\mathrm{X}=\mathrm{Br}$, I) são as mais reativas (arilos, benzilos ou vinilos).

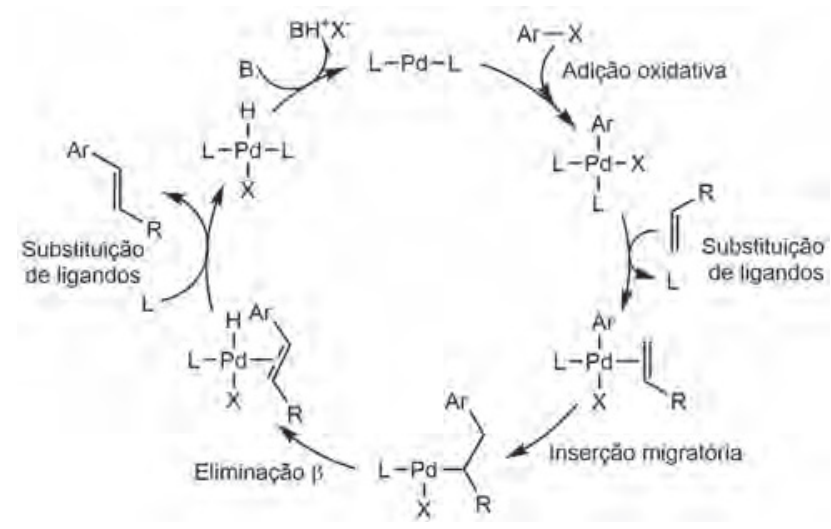

Esquema 5 - Mecanismo da reação de Heck com carga neutra no complexo de Pd. 
Os cloretos, $\mathrm{Cl}-\mathrm{C}\left(\mathrm{sp}^{2}\right)$ e os halogenetos de alquilo, $\mathrm{X}-\mathrm{C}\left(\mathrm{sp}^{3}\right)$ são menos reativos. Para um dado arilo a reatividade decresce com a natureza de $\mathrm{X}$ grosso modo na ordem inversa do aumento de energia da ligação $\mathrm{Ar}-\mathrm{X}$ :

$$
\mathrm{N}_{2}^{+}>\mathrm{I}>\mathrm{OTf} \approx \mathrm{Br}>\mathrm{Cl}>\mathrm{OTs}>>\mathrm{F}>\mathrm{OMe}
$$

Em termos do substrato, a reatividade relativa dos alcenos em reações de competição decresce na ordem da Figura 2:

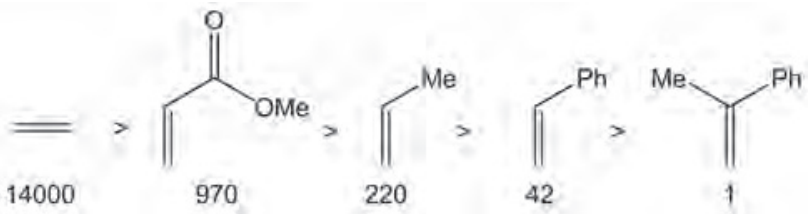

Figura 2 - Ordem de reatividade relativa dos alcenos com um dado arilo.

A estereosseletividade da arilação conduz maioritariamente a alcenos com configuração $E$ (ou trans) de acordo com o mecanismo descrito no esquema 6 . A repulsão estereoquímica dos substituintes Ar e R leva-os a afastarem-se, favorecendo a formação do estereoisómero $E$.

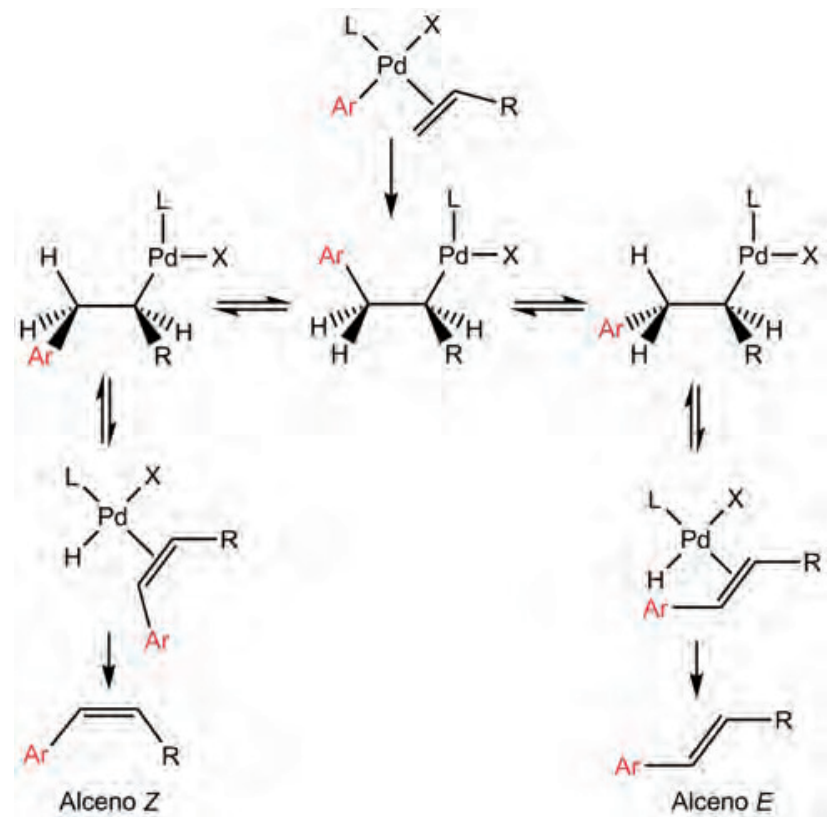

Esquema 6 - Estereosseletividade da reação de Heck. O produto com configuração $E$ é favorecido sobre o $Z$.

A regiosseletividade da reação foi inicialmente estabelecida por Heck (1978) com base na adição de bromobenzeno a diversos alcenos (esquema 7) [14]. Como se pode ver as posições terminais (não substituídas) são francamente preferidas para a adição do arilo. No caso de alcenos internos as posições com substituintes menos volumosos são favorecidas, tudo indicando que a regiosseletividade é controlada pela estereoquímica.

Os precursores de $\mathrm{Pd}$ são tipicamente $\mathrm{Pd}(\mathrm{OAc})_{2}$, $\mathrm{Pd}(\mathrm{dba})$ ou $\mathrm{Pd}_{2}(\mathrm{dba})_{3}$. O primeiro é reduzido por uma variedade de reagentes que podem estar presentes na mistura reacional, como alceno, fosfina, álcool (solvente), amina (base). Os outros são complexos estáveis de $\mathrm{Pd}^{0}$ com dibenzilideno acetona (dba) (Figura 3).

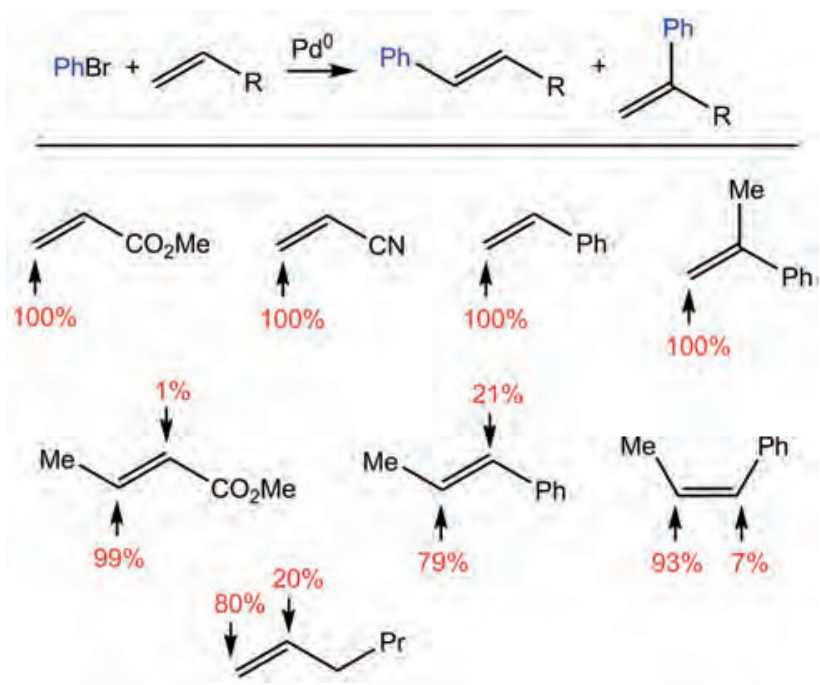

Esquema 7 - Regiosseletividade da reação de $\mathrm{PhBr}$ com variados alcenos. Os valores numéricos são a percentagem do produto arilado formado na reação de Heck.<smiles>O=C(/C=C/c1ccccc1)/C=C/c1ccccc1</smiles>

Figura 3 - Dibenzilideno acetona.

Os solventes podem variar numa gama imensa de polaridades como sejam: tolueno, THF, $\mathrm{MeOH}, \mathrm{H}_{2} \mathrm{O}$, DMF ou mesmo DMSO. As fosfinas são normalmente $\mathrm{PPh}_{3}$ ou $\mathrm{P}$ (tolilo) $)_{3}$ exceto em casos especiais como o das fosfinas quirais necessárias para induzir assimetria na reação de Heck (ver abaixo). As bases mais vulgarmente usadas são $\mathrm{NEt}_{3}, \mathrm{Cy}_{2} \mathrm{NEt}$, NaOAc e $\mathrm{Na}_{2} \mathrm{CO}_{3}$ e as reações têm lugar normalmente acima de $100{ }^{\circ} \mathrm{C}$. No entanto, esta temperatura baixa nas condições do protocolo de Jeffery que usa bases insolúveis como $\mathrm{K}_{2} \mathrm{CO}_{3}$, um equivalente de $\mathrm{NBu}_{4} \mathrm{Cl}$ como catalisador de transferência de fase e DMF como solvente. A reação acelera de tal modo que pode ser feita à temperatura ambiente em alguns casos [15].

A adição de $\mathrm{AgNO}_{3}$ à mistura reacional é uma outra modificação importante. A precipitação de AgX forma o catalisador catiónico [PdArL $]^{+}$favorecendo a coordenação do alceno e tornando praticamente irreversível o passo da eliminação $\beta$. Assim sendo, acelera-se a reação, inibe-se a isomerização do alceno (indesejada) e altera-se o controle da regiosseletividade. De facto, a coordenação do alceno ao catalisador polariza a ligação $\mathrm{C}=\mathrm{C}$ coordenada de modo a que o carbanião do arilo ou vinilo migra seletivamente para o carbono com a carga $\delta^{+}$mais elevada. O controlo regioquímico existente no caso dos catalisadores neutros $\left(\mathrm{PdL}_{2}\right)$ é ultrapassado pelo efeito eletrónico. O uso de triflatos (ArOTf) em vez de halogenetos, produz o mesmo efeito da adição de $\mathrm{Ag}^{+}$, pois os triflatos de Pd são essencialmente iónicos. No esquema 8 compara-se a regiosseletividade da arilação de alguns alcenos usando triflatos de arilo ou halogenetos de arilo [16].

Para além da clássica adição de arilo, benzilos e vinilos a olefinas também é possível adicionar heterociclos como indóis, tiazóis, oxazóis, pirróis, furanos e piridinas ativadas, como exemplificado no esquema 9. 

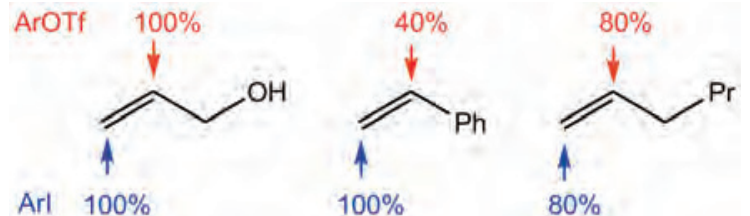

Esquema 8 - Regiosseletividade das arilações de Heck com iodetos de arilo (a azul) e com triflatos de arilo (a vermelho). Os valores numéricos são a \% do produto final arilado na posição indicada.
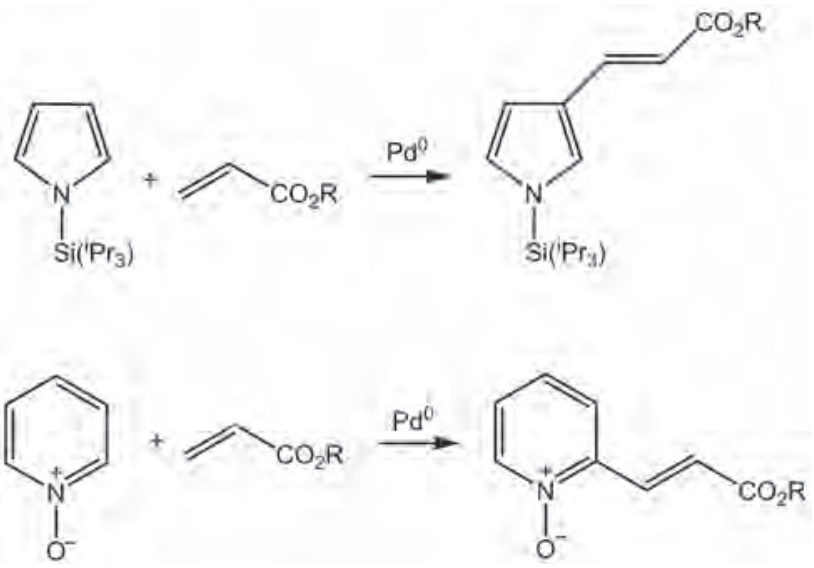

Esquema 9 - Exemplos de reações de Heck em heterociclos.

Na conclusão do seu primeiro artigo de 1967 Heck escreve: "A reação de arilação de olefinas proporciona portanto um caminho muito conveniente para uma extensa variedade de derivados de olefinas." Como se veio a demonstrar, este é mais um daqueles monumentais "understatements” da História da Ciência. De facto, ela constituiu uma ferramenta totalmente inovadora da síntese orgânica que lentamente foi adquirindo maior importância até se tornar quase omnipresente na atual estratégia de síntese. Para se ter uma ideia do seu lento mas inexorável avanço, note-se que em 1982 Heck publicou um capítulo no Organic Reactions onde, em 45 páginas, descrevia toda a quí-
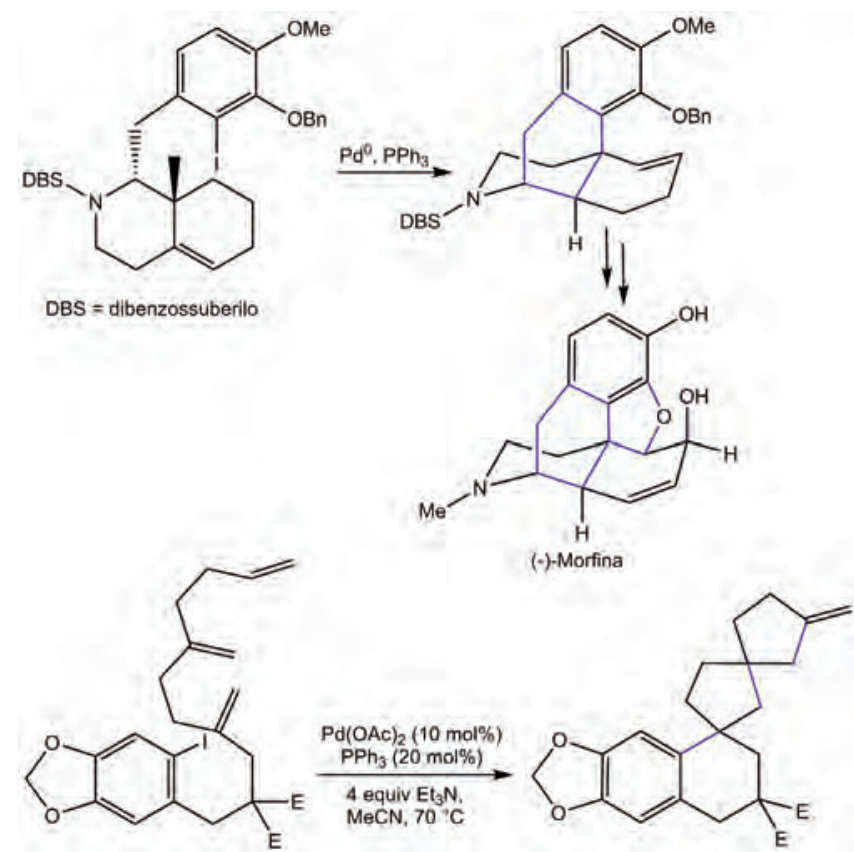

Esquema 10 - Exemplos de formação de anéis complexos (a azul) usando reações de Heck. O exemplo de baixo é uma cascata de Heck $s p^{2}$. mica realizada com esta tecnologia, desde 1967. Em 2002, a descrição limitada apenas às reações de Heck intramoleculares ocupava 377 páginas. O livro “The Mizoroki-Heck reaction”, de 2006 tem 600 páginas.

Perante esta vastíssima panóplia de aplicações em síntese orgânica, e em particular em química medicinal, não é fácil escolher exemplos para apresentar num texto deste cariz $[17,18]$. Sem embargo, no esquema 10 ilustram-se duas reações de ciclização, um tipo de transformação que habitualmente coloca questões de muito difícil abordagem na síntese de produtos naturais. No esquema 10 ilustra-se o poder da reação de Heck na síntese da (-)-morfina [19], e da formação em cascata de 3 anéis alicíclicos (reação em cascata ou zipper) [20].

O uso de fosfinas quirais pode condicionar a estereoquímica da inserção migratória levando à formação de produtos de forma enantiosseletiva. Este processo ainda aumenta o valor da reação de Heck normal, particularmente na síntese de produtos naturais, como se pode ver no esquema 11 com a síntese de (+)-xestoquinona, um potente inibidor de proteínas oncogénicas, extraído duma esponja marinha. Note-se que o primeiro passo é uma reação tandem que envolve duas reações de Heck, a primeira das quais é enantiosseletiva [21].

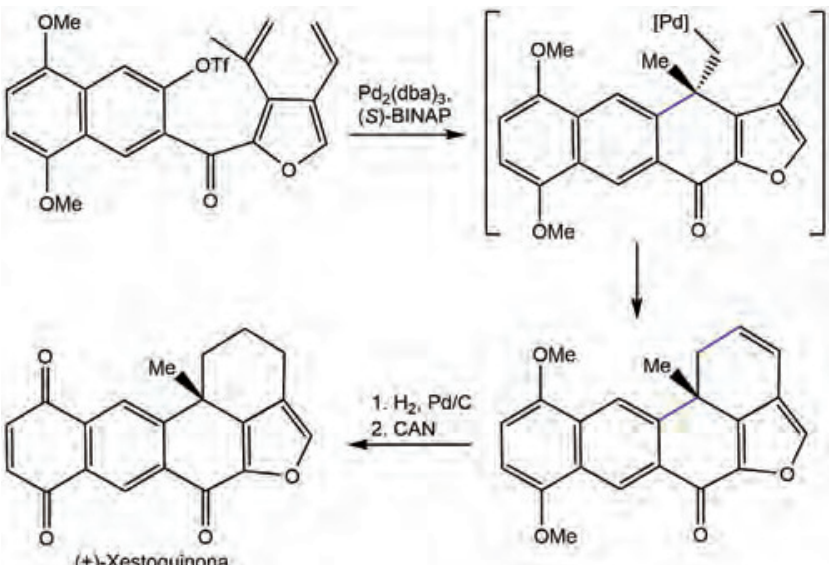

Esquema 11 - Duplo acoplamento de Heck (ligações a azul) usado na síntese da (+)-xestoquinona. O primeiro intermediário (entre parêntesis) resulta da versão enantiosseletiva da reação de Heck, proporcionada pelo uso da fosfina quiral (S)-BINAP. O segundo acoplamento fecha o anel de 6 membros.

Há muitas outras reações tandem de Heck nas quais o Pd catalisa mais do que um passo reacional, após uma primeira ativação duma ligação R-X. De facto, se atentarmos no mecanismo do esquema 5 , a espécie insaturada gerada após a inserção migratória pode reagir intra ou intermolecularmente com outras funções, caso a eliminação $\beta$ não ocorra ou não possa ocorrer. O esquema 12 mostra várias das possibilidades desta química riquíssima na qual o químico orgânico de síntese pode espraiar a sua imaginação e criatividade.

As aplicações na indústria e investigação farmacêutica são inúmeras mas os produtos mais conhecidos que envolvem a reação de Heck são o naproxeno (anti-inflamatório não esteroide) e o metoxicinamato de octilo (écran de UV em cremes solares) (Figura 4).

Testemunha calma, aparentemente tímida e reservada de toda esta revolução, Richard Heck retirou-se para a Fló- 


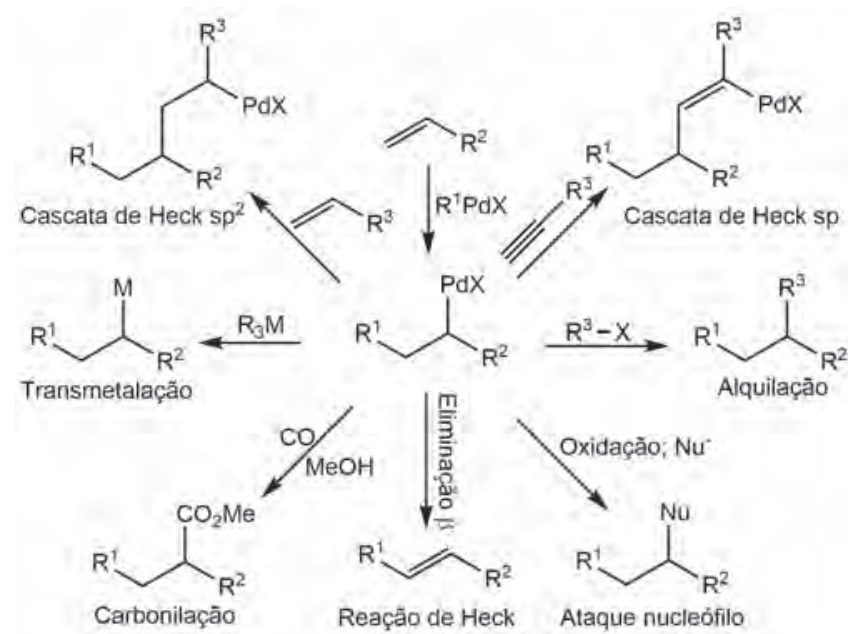

Esquema 12 - Possíveis ramificações reacionais do intermediário central da reação de Heck.
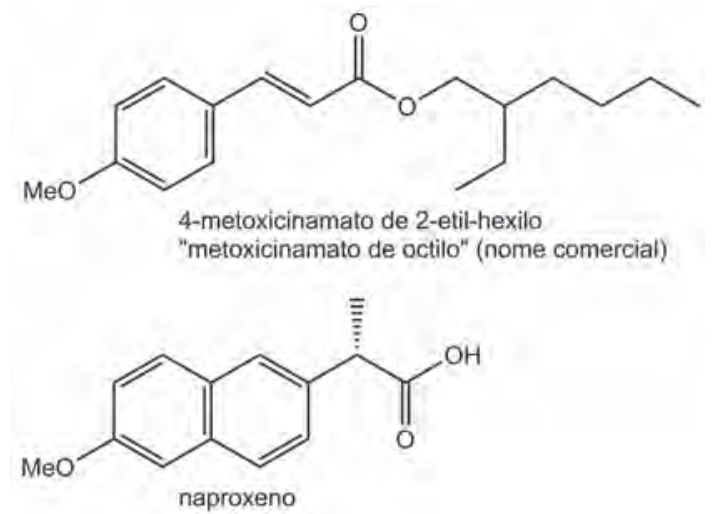

Figura 4 - Produtos de grande consumo produzidos industrialmente por via da reação de Heck.

rida em 1989, quando o seu financiamento foi cancelado e não conseguiu obter fundos públicos ou privados para a sua investigação! Talvez os amantes da bibliometria justifiquem isto rapidamente pois certamente consideram modesto o volume do trabalho publicado de Heck: 120 artigos (Web of Science), $h$ index $=57$ e $n^{0}$ de citações por artigo: 114,11.

Todavia, o impacto do seu trabalho (entre 1980 e 2015, havia cerca de 120 mil menções da reação de Heck na literatura) tornou irrelevante e risível qualquer apreciação bibliométrica tirando-o lentamente da sombra e trazendo-lhe o reconhecimento ativo da comunidade científica. Em 2004 a Universidade do Delaware estabeleceu a cátedra com o seu nome (Richard F. Heck Lectureship). Em 2005 recebeu o William Carothers Award que reconhece inovação química com elevado impacto comercial. Em 2006 recebeu o Herbert C. Brown Award for Creative Research in Synthetic Methods atribuído pela American Chemical Society e patrocinado pela Universidade de Purdue. Finalmente, em 2010, foi agraciado com o Prémio Nobel da Química que compartilhou com dois dos principais exploradores das sequelas da sua química: Ei-ichi Negishi e Akira Suzuki.

O ponto de partida para uma série de reações de formação de ligações C-C catalisadas por Pd, e desenvolvidas na segunda metade da década de 1970, é a espécie resultante da adição oxidativa do esquema 5: [PdRXL ${ }_{2}$ ou equivalente. Se for alquilada com um reagente R'M para dar [PdRR' $\mathrm{L}_{2}$ ] uma eliminação redutiva posterior regenera
$\mathrm{PdL}_{2}$ e forma o produto de acoplamento R-R'. Estas reações diferem essencialmente na natureza de $\mathrm{M}^{\prime}$, podem acoplar $\mathrm{C}\left(s p^{2}\right)-\mathrm{C}\left(s p^{3}\right), \mathrm{C}\left(s p^{2}\right)-\mathrm{C}\left(s p^{2}\right)$ (acoplamentos de Stille, Negishi, Suzuki, Hiyama e Kumada) e C( $\left.s p^{2}\right)-\mathrm{C}(s p)$ (acoplamento de Sonogashira) e revolucionaram a síntese orgânica. Serão objeto dum outro artigo, dada a sua semelhança mecanística. Em boa verdade tanto o acoplamento de Sonogashira como o de Suzuki foram descobertos por Heck em 1975. O primeiro foi depois aperfeiçoado por Sonogashira que introduziu um passo de ativação do alcino. $\mathrm{O}$ segundo foi aperfeiçoado por Suzuki para se tornar numa metodologia extremamente abrangente e suave do ponto de vista de impacto ambiental. Para além destas derivações, há outras extensões da reação de Heck, como a oxoarilação de Heck, a reação de Heck desidrogenativa (ativação Ar-H), a reação de amino-Heck (acoplamento $\mathrm{C}-\mathrm{H}$ ) e muitas outras variantes experimentais como a reação em líquidos iónicos ou com nanopartículas de Pd. Basta googlar!

Decisivamente, a criatividade e a inovação, marcaram a carreira científica de Richard Heck, cientista de postura tranquila e modesta, forjado em ambientes de altíssima qualidade científica e protegido da permanente "distração" da vida académica pelos muros da "sua” fábrica de pólvora onde encontrou o ambiente e os meios para uma pesquisa livre e profunda. $\mathrm{O}$ seu projeto começou por ser a pesquisa de polímeros vinílicos e acabou mudando para sempre o papel desses e doutros monómeros. Tudo por força de aliar a sua curiosidade à inexorável tendência do Pd para orquestrar adições oxidativas e eliminações redutivas, coordenar alcenos e facilitar a eliminação $\beta$ ! Devido a um colega seu se queixar da irritante ubiquidade desta última, Heck cogitou sobre o que se passaria se usasse um substituinte que não pudesse sofrer tal eliminação. Fez reagir $\mathrm{PhHg}(\mathrm{OAc})$ com $\left[\mathrm{PdCl}_{4}\right]^{2-}$ sob uma atmosfera de $\mathrm{C}_{2} \mathrm{H}_{4}$ e viu precipitar $\mathrm{Pd}$ metálico enquanto o etileno era rapidamente incorporado em estireno (80\%) e estilbeno (20\%). Estava descoberta a reação de Heck que mudou a história da Química duma forma particularmente invulgar pois duvido que tenha havido mais alguém que publicasse sozinho seis artigos com este impacto no mesmo número do JACS!

Segundo os media, o seu maior sucesso é atribuído ao acoplamento alceno-alcino (Sonogashira) que é usado para a marcação de bases de DNA com sondas fluorescentes, num processo que permitiu a automação da sequenciação do DNA no Human Genome Project. Porventura, do ponto de vista comercial e também do nosso "way of life", o maior impacto parece resultar da aplicação da sua química na síntese farmacêutica e na síntese dos materiais que permitem o fabrico de circuitos mais finos e materiais para écrans de telemóveis inteligentes e outros aparelhos controlados por computador. Quanto aos fármacos um colega seu disse a um jornalista do NY Times: "se tomar um remédio para qualquer coisa, agradeça ao Dick”. Quanto aos materiais, a Dow agradeceu-lhe com o anúncio reproduzido na Figura 5.

Em 2006 radicou-se nas Filipinas donde a sua mulher era natural. Como foi um apaixonado das plantas desde a sua infância não admira que a sua derradeira atividade tenha sido o cultivo de orquídeas. Sem ressentimentos nem falsas modéstias disse numa das suas raras entrevistas: "Não estou a fazer mais química nenhuma mas penso que já fiz a minha parte”. 

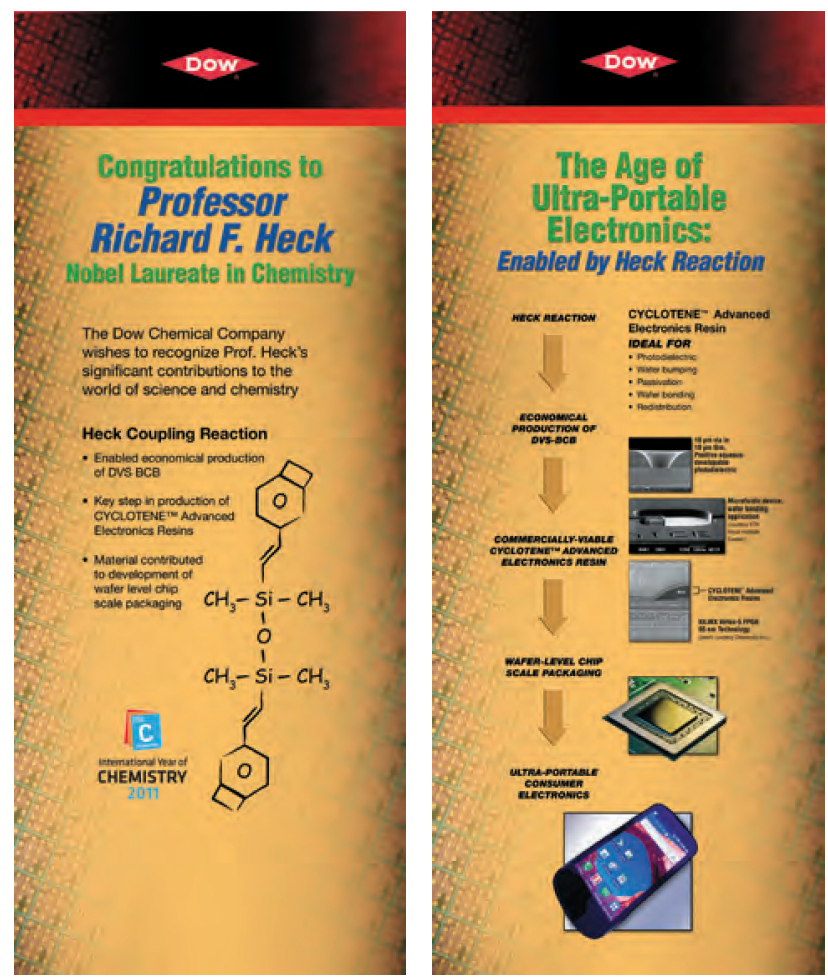

Figura 5 - Poster da Dow Chemicals homenageando Heck pelo Prémio Nobel.

\section{Referências}

[1] B. Cornils, W.A. Herrmann, M. Rasch, Angew. Chem. Int Ed. 33 (1994) 2144-2163.
[2] R.F. Heck, D.S. Breslow, J. Am. Chem. Soc. 83 (1961) 4023-4027.

[3] C.A. Tolman, Chem. Soc. Rev. 1 (1972) 337-353.

[4] R.F. Heck, D.S. Breslow, J. Am. Chem. Soc. 82 (1960) 750-751.

[5] R.F. Heck, J. Am. Chem. Soc. 90 (1968) 5518-5526.

[6] R.F. Heck, J. Am. Chem. Soc. 90 (1968) 5526-5531.

[7] R.F. Heck, J. Am. Chem. Soc. 90 (1968) 5531-5538.

[8] R.F. Heck, J. Am. Chem. Soc. 90 (1968) 5538-5542.

[9] R.F. Heck, J. Am. Chem. Soc. 90 (1968) 5542-5546.

[10] R.F. Heck, J. Am. Chem. Soc. 90 (1968) 5546-5548.

[11] T. Mizoroki, K. Mori, A. Ozaki, Bull. Chem. Soc. Jpn. 44 (1971) 581.

[12] R.F. Heck, J.P. Nolley, J. Org. Chem. 37 (1972) 2320-2322.

[13] H.A. Dieck, R.F. Heck, J. Am. Chem. Soc. 96 (1974) 1133-1136.

[14] R.F. Heck, Pure Appl. Chem. 50 (1978) 691-701.

[15] T. Jeffery, Tetrahedron: Asymmetry 52 (1996) 101131130.

[16] W. Cabri, I. Candiani, Acc. Chem. Res. 28 (1995) 2-7.

[17] J.G. De Vries, Can. J. Chem. 79 (2001) 1086-1092.

[18] F.-X. Felpin, L. Nassar-Hardy, F. Le Callonnec, E. Fouquet, Tetrahedron: Asymmetry 67 (2011) 2815-2831.

[19] C.Y. Hong, N. Kado, L.E. Overman, J. Am. Chem. Soc. 115 (1993) 11028-11029.

[20] M.M. Abelman, L.E. Overman, J. Am. Chem. Soc. 110 (1988) 2328-2329.

[21] S.P. Maddaford, N.G. Andersen, W.A. Cristofoli, B.A. Keay, J. Am. Chem. Soc. 118 (1996) 10766-10773.

\section{Atualidades Científicas}

\section{Catalisador suportado num balão de vidro}

As nanopartículas de metais nobres possuem atividade catalítica relevante. Uma vez que estes materiais são dispendiosos, o interesse pela sua recuperação e reutilização após a sua atividade catalítica tem aumentado nos últimos anos. Uma abordagem para facilitar a separação e recuperação do catalisador após a reação é a sua imobilização num substrato de suporte, o qual pode ser separado da mistura reacional por meios físicos (centrifugação ou filtração, por exemplo). No entanto, frequentemente é necessário um trabalho laborioso após a separação para restaurar o catalisador à sua forma inicial e durante o qual há necessariamente perdas do mesmo. Intuitivamente, a situação ideal seria que o catalisador estivesse suportado diretamente nas paredes internas do reator e, portanto, pudesse ser reutilizado sem necessidade de proceder aos processos onerosos de recuperação.

Investigadores da Tailândia e da Suíça desenvolveram um sistema catalítico reutilizável de nanopartículas de paládio que pode ser aplicado às paredes internas de um reator de vidro. A equipa começou por depositar nanofilamentos de silicone (SNF) sobre o vidro usando $\mathrm{CH}_{3} \mathrm{SiCl}_{3}$ como precursor e a superfície obtida foi posteriormente revestida com polidopamina. As nanopartículas de paládio foram então geradas in situ por imersão das fibras funcionalizadas numa solução de $\mathrm{K}_{2} \mathrm{PdCl}_{4}$ tendo-se ligado fortemente à superfície modificada de $\mathrm{SNF}$. A equipa testou o sistema catalítico SNF-Pd numa reação de acoplamento cruzado de Heck e obteve uma atividade e seletividade elevada, superior à do sistema tradicional $\mathrm{Pd} / \mathrm{C}$. O nanocatalisador pôde ser reutilizado simplesmente após lavagem do reator com acetato de etilo e etanol. Mesmo após 20 ciclos de reutilização, foram obtidos rendimentos de 90\%. Esta abordagem é altamente versátil e, segundo os autores, pode ser aplicada a reatores químicos de laboratório de diferentes formas, tamanhos e configurações e ainda ser estendida a nanopartículas de outros metais.

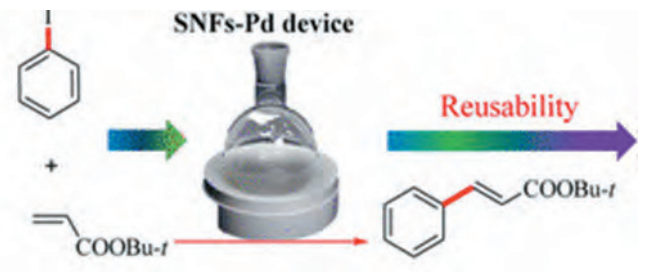

\section{Fontes:}

Glassware with a Built-In Catalyst, http://www.chemistryviews. org/details/news/10478746/Glassware_with_a_Built-In_Catalyst. html?elq_mid=16128\&elq_cid=3941189 (Acedido em 03/04/2017)

X. Fei, W. Kong, X. Chen, X. Jiang, Z. Shao, J. Y. Lee. A recyclingfree nanocatalyst system: the stabilization of in situ-reduced noble metal nanoparticles on silicone nanofilaments via a mussel-inspired approach. ACS Catal. 7 (2017) 2412-2418. 